\title{
Characteristics of Liquid Hold-ups in a Soaked and Unsoaked Fixed Bed
}

\author{
Hirotoshi KAWABATA, Zhigang LIU, ${ }^{1)}$ Fumio FUJITA ${ }^{2)}$ and Tateo USUI \\ Department of Materials and Manufacturing Science, Graduate School of Engineering, Osaka University, 2-1 Yamadaoka, \\ Suita, Osaka 565-0871 Japan. 1) Formerly Graduate Student of Osaka University; Now at Alcoa Closure Systems \\ Japan, Ltd., 148, Nogi, Nogi-machi, Shimotsuga-gun, Tochigi 329-0114 Japan. $\quad 2$ 2) Formerly Graduate Student of Osaka \\ University; Now at NTT DoCoMo, Inc., Kokusai Akasaka Bldg.18F 4-5, Akasaka 2-chome, Minato-ku, Tokyo 107-0052 Japan.
}

(Received on June 2, 2005; accepted on July 21, 2005)

\begin{abstract}
In most previous works, liquid hold-ups were studied by using a cold model of a fixed bed soaked prior to experiments. However, they did not consider that the dripping zone of a blast furnace is saturated with liquids or with evenly distributed droplets. In the present study, the characteristics of liquid hold-ups and liquid flow were investigated by using a one-dimensional cold model of a fixed bed soaked and unsoaked prior to experiments (initially soaked and unsoaked beds). Packed balls were five kinds, the diameters $\left(D_{p}\right)$ of which ranged from 5.4 to $30 \mathrm{~mm}$. Tap water was used as liquid. Contact angles $(\theta)$ for these particle/liquid systems were about $70^{\circ}$ and $10^{\circ}$ for fluorine-coated particles and non-coated particles, respectively.

Although, under bad wettability condition $\left(\theta \fallingdotseq 70^{\circ}\right)$, total and static hold-ups for initially unsoaked bed packed with small balls are remarkably smaller than those for initially soaked bed, the difference in their hold-ups between initially unsoaked and soaked beds decreases with increasing ball size in the bed. In initially soaked bed, total and static hold-ups increase monotonically as ball size decreases, which means the specific surface area increases. On the other hand, in initially unsoaked bed, total and static hold-ups under bad wettability condition indicate maximum values at about $D_{\mathrm{p}}=10 \mathrm{~mm}$ and decrease abruptly in proportion to a decrease in particle size, despite an increase in the specific surface area. Only restricted liquid droplets and/or liquid rivulets are formed within the packed bed with good wettability condition $\left(\theta \fallingdotseq 10^{\circ}\right)$ for initially unsoaked bed, nevertheless liquid is easy to spread out on the solid surface. The influence of the initial bed condition, soaked or unsoaked bed, on liquid hold-ups is great under bad wettability condition.
\end{abstract}

KEY WORDS: ironmaking; blast furnace; dripping zone; fixed bed; liquid hold-ups; particle/liquid wettability; initially soaked and unsoaked beds.

\section{Introduction}

In the lower part of a blast furnace (BF), there are "socalled" four kinds of fluids, gas (gas phase), coke (solid phase), molten metal and slag (liquid phase), and coke powder or pulverized coal (powder phase) at high temperatures. ${ }^{1)}$ Those flow (moving) characteristics in the dripping zone, the vicinity of raceway and deadman have not been clarified so much, because the four fluids flow in complicated manners and affect and react with each other.

In most previous works ${ }^{2-6)}$ liquid hold-ups were investigated by using a cold model of a fixed bed which was soaked prior to experiments (hereinafter called initially soaked bed). The characteristics of liquid hold-ups for BF should be investigated by using a moving bed unsoaked prior to experiments (hereinafter called initially unsoaked bed), because the burden continually descends and is not completely wetted in the lower part of BF. A fixed bed unsoaked initially was used in only a few works, ${ }^{7,8)}$ except for our previous studies with one-dimensional (1D) ${ }^{9)}$ and twodimensional (2D) cold models ${ }^{10,11)}$ which simulated the lower part of BF by using fixed and moving beds unsoaked initially.

Liquid hold-ups and liquid flow distribution through 2D model of initially unsoaked fixed bed were different from those through initially soaked fixed bed ${ }^{10)}$ as follows: A packed column of the present author's previous 2D model was a rectangular parallelepiped with $655 \mathrm{~mm}$ in height, $500 \mathrm{~mm}$ in width, and $60 \mathrm{~mm}$ in depth. Filtered tap water was used as liquid. Particles used were stainless steel balls of $6.4 \mathrm{~mm}$ in diameter and coated with fluorine; as the index on liquid/particle wettability, the contact angle $(\theta)$ was about $90^{\circ}$. Figure 1 shows that total hold-up $\left(\mathrm{H}_{t} ; \mathrm{O}\right)$ and static hold-up $\left(\mathrm{H}_{\mathrm{S}} ; \triangle\right)$ for initially unsoaked bed are remarkably smaller than those $(\boldsymbol{O}, \mathbf{\Delta})$ for initially soaked bed, but dynamic hold-ups for initially unsoaked and soaked beds $\left(\mathrm{H}_{\mathrm{d}} ; \square, \boldsymbol{\square}\right)$ are similar to each other. $\mathrm{H}_{\mathrm{S}}(\boldsymbol{\Delta})$ for initially soaked bed is almost independent of the liquid velocity (superficial velocity $V_{\mathrm{L}}$ ) and shows practically constant value, which agrees with an equation by Fukutake et al. ${ }^{6}$ ) However, $H_{S}(\triangle)$ for initially unsoaked bed lies remote from the calculated one. The liquid flow distributions through 2D model of initially soaked and unsoaked fixed beds are shown in Fig. 2. The liquid flow distribution 


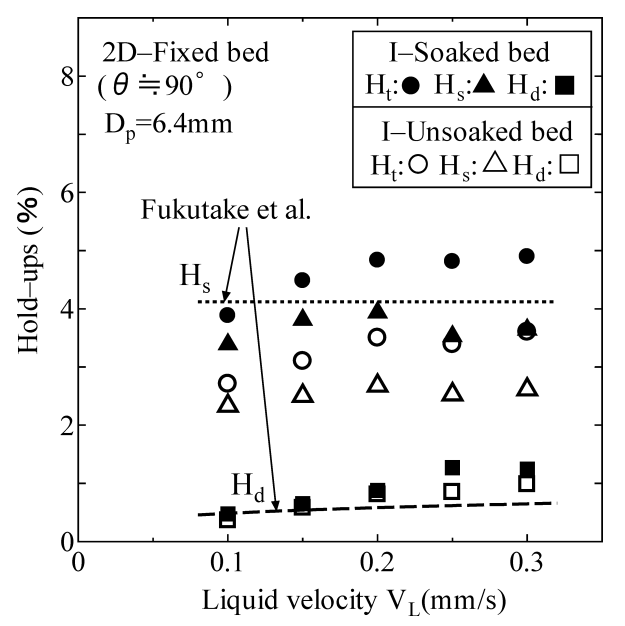

Fig. 1. Comparison between hold-ups estimated from Fukutake et al.'s equation ${ }^{6}$ and present authors' ones ${ }^{10,11)}(2 \mathrm{D}$ model).

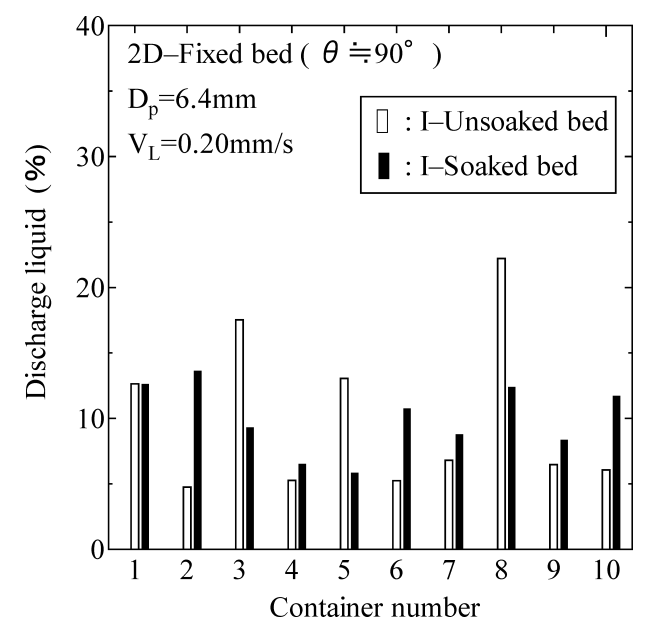

Fig. 2. Difference of liquid flow distributions through initially soaked and unsoaked fixed beds (2D model).

through initially soaked bed is rather uniform, while the one through initially unsoaked bed is far from uniform.

Thus, whether the initial bed condition is soaked or unsoaked affects the liquid flow behavior greatly. However, the particles used were $6.4 \mathrm{~mm}$ in diameter, which is relatively smaller than the coke size in the lower part of BF. It is not ascertained whether the similar liquid flow behavior arises in the case of larger particles or not. It is difficult to use larger particles, because the packed column of our 2D model has a relatively narrow depth $(60 \mathrm{~mm})$ as mentioned above.

In the present study, the characteristics of liquid hold-ups and liquid flow behavior were investigated through initially soaked and unsoaked fixed beds of 1D cold model with a diameter of $200 \mathrm{~mm}$. Five diameters of packed particles used were 5.4, 8.1, 10, 19 and $30 \mathrm{~mm}$. As the filtered tap water was used, $\theta$ for these particle/liquid systems were about $70^{\circ}$ and $10^{\circ}$ for fluorine-coated and non-coated particles, respectively.

\section{Experimental}

\subsection{Experimental Apparatus}

A packed column of 1D model was made of transparent acrylic resins tube with an inside diameter of $200 \mathrm{~mm}$ and a

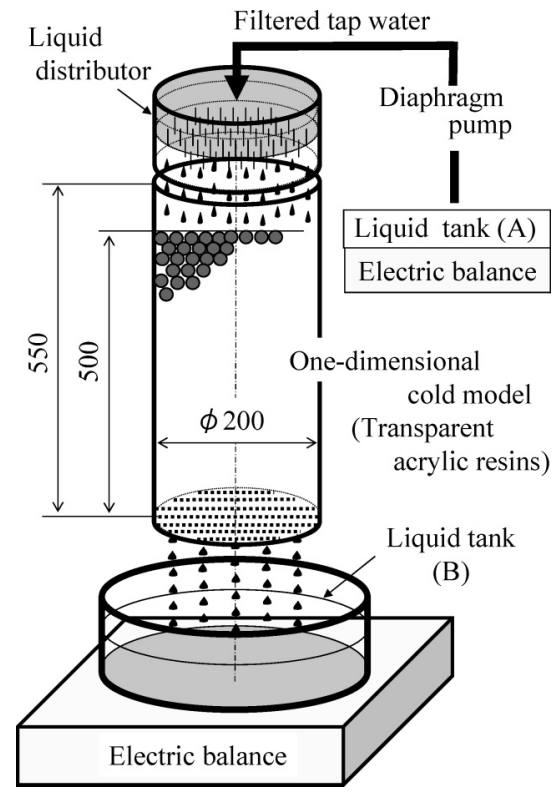

Fig. 3. Schematic layout of the one-dimensional cold model; dimensions in $\mathrm{mm}$.

height of $550 \mathrm{~mm}$, as shown in Fig. 3. The packed height of particles was $500 \mathrm{~mm}$. The superficial volume of the empty bed was $15700 \mathrm{~cm}^{3}$, which is almost the same as that of the previous 2D model. ${ }^{10,11)}$ To reduce the wall surface effect of the packed column on the liquid distribution and hold-ups, the inner surface was coated with fluorine. Alumina balls of $5.4,8.1$ and $10 \mathrm{~mm}$, and glass balls of $19 \mathrm{~mm}$ and $30 \mathrm{~mm}$ in diameter were used as packing particles. The measured void fraction $(\varepsilon)$ increased from 0.36 to 0.42 as particle diameters increased from $5.4 \mathrm{~mm}$ to $30 \mathrm{~mm}$. Fluorine-coated particles and non-coated particles were used to examine the influence of the particle/liquid wettability on liquid holdups. As the filtered tap water was used, $\theta$ of the particle/liquid were about $70^{\circ}$ and $10^{\circ}$ for fluorine-coated particles and non-coated particles, respectively. A liquid distributor installed above the packed bed was composed of 148 injection needles of $0.5 \mathrm{~mm}$ I.D. and $30 \mathrm{~mm}$ in length to disperse liquid uniformly on the top surface of the packed bed. Filtered tap water, which was pumped up from liquid tank (A) by using a diaphragm pump, was supplied to the liquid distributor. The decrease in water mass of liquid tank (A) was measured continuously by an electric balance. The increase in mass of water draining into liquid tank (B) from the packed bed was also measured continuously by another electric balance (Fig. 3). By using thin injection needles, inflow into the packed bed was able to be quickly stopped by switching off the pump, because water could not drip from the thin needles with high flow resistance. Therefore, the volume of inflow into the packed bed could be accurately measured.

\subsection{Definition and Measurement of Liquid Hold-ups}

\subsubsection{Initially Unsoaked Bed}

Water was irrigated from the top of the packed bed with the liquid distributor, and the volume of outflow from the bed into the liquid tank (B) was measured continuously. Sometime after the rate of outflow became steady, water supply was stopped, and the total liquid draining volume was measured continuously until liquid draining from the 


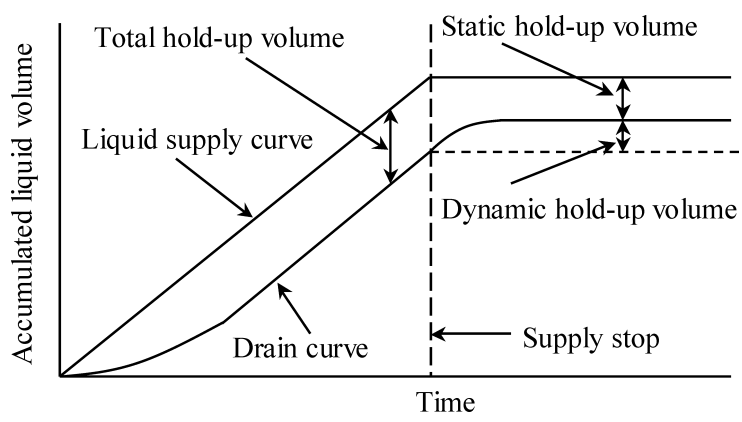

Fig. 4. Scheme of liquid supply curve, drain curve and hold-up volumes in fixed bed.

bed stopped. Figure 4 schematically illustrates liquid supply curve, liquid drain curve and three hold-up volumes. The liquid volume existing in the packed bed is classified as follows ${ }^{12)}$ :

(1) Total liquid volume (the liquid volume remaining in the packed bed when the liquid is being supplied, namely the difference between total supply volume and total drain volume.)

(2) Dynamic liquid volume (the liquid volume flowing in the packed bed, namely the draining liquid volume after the liquid supply was stopped.)

(3) Static liquid volume (the liquid volume standing in the packed bed, namely the liquid volume standing still on the surface of particles and on the spaces between the particles or particles and wall after the liquid supply was stopped.)

Those liquid volumes divided by superficial total volume of the packed bed are defined as total hold-up $\left(\mathrm{H}_{t}\right)$, dynamic hold-up $\left(\mathrm{H}_{\mathrm{d}}\right)$ and static hold-up $\left(\mathrm{H}_{\mathrm{S}}\right)$, respectively. Still, the measured static hold-up $\mathrm{H}_{\mathrm{Sm}}$ includes the liquid hold-up $\mathrm{H}_{\mathrm{Sw}}$ which sticks to the inner surface of wall in the empty packed column; $\mathrm{H}_{\mathrm{Sw}}$ varies depending on the size of the packed column, namely, the inner surface area and the superficial volume of the packed column. Therefore, $\mathrm{H}_{\mathrm{Sw}}$ should be subtracted from the measured static hold-up $\mathrm{H}_{\mathrm{Sm}}$. In the present experiment, measured $\mathrm{H}_{\mathrm{Sw}}$ on the wall in the empty column was $0.41 \%$, and therefore $\mathrm{H}_{\mathrm{S}}$ was evaluated by subtracting 0.41 from $\mathrm{H}_{\mathrm{Sm}}$.

These hold-ups have the following relationship:

$$
\mathrm{H}_{\mathrm{t}}=\mathrm{H}_{\mathrm{d}}+\mathrm{H}_{\mathrm{S}}
$$

\subsubsection{Initially Soaked Bed}

Packed bed was soaked through prior to experiments by quickly pouring the water of half as large as the superficial volume of the packed bed from the top. The difference between inflow and outflow volumes was measured in order to determine static liquid volume standing in the packed bed before irrigation. Then, water was irrigated from the top of the packed bed with the liquid distributor, and the outflow volume into liquid tank (B) from the bed was measured continuously. Sometime after the outflow rate became steady, the water supply was stopped, and the total liquid draining volume was measured continuously until the draining stopped.

\subsection{Experimental Conditions}

Table 1 compares the conditions and dimensionless
Table 1. Comparison of conditions for present experiments and a blast furnace.

\begin{tabular}{|c|c|c|c|}
\hline & $\begin{array}{c}\text { One-dimensional } \\
\text { cold model }\end{array}$ & \multicolumn{2}{|c|}{ Blast furnace } \\
\cline { 2 - 4 } & Fixed bed & Metal & Slag \\
\hline $\boldsymbol{D}_{\mathrm{p}}(\mathrm{mm})$ & $5.4,8.1,10,19,30$ & \multicolumn{2}{|c|}{$30 \sim 60$} \\
\hline$\rho_{\mathrm{L}}\left(\mathrm{kg} / \mathrm{m}^{3}\right)$ & 1000 & 6600 & 2600 \\
\hline $\boldsymbol{V}_{\mathrm{G}}(\mathrm{m} / \mathrm{s})$ & 0 & \multicolumn{2}{|c|}{$1.2 \sim 1.7$} \\
\hline $\boldsymbol{V}_{\mathrm{L}}(\mathrm{mm} / \mathrm{s})$ & $0.07 \sim 0.35$ & \multicolumn{2}{|c|}{$0.09 \sim 0.15$} \\
\hline $\boldsymbol{V}_{\mathrm{S}}(\mathrm{mm} / \mathrm{s})$ & 0 & \multicolumn{2}{|c|}{$0.10 \sim 0.60$} \\
\hline$\mu_{\mathrm{L}}(\mathrm{Pa} \cdot \mathrm{s})$ & 0.0010 & 0.005 & 0.3 \\
\hline$\sigma_{\mathrm{L}}(\mathrm{N} / \mathrm{m})$ & 0.072 & 1.1 & 0.48 \\
\hline$\theta(\mathrm{deg})$ & $10^{\circ}, 70^{\circ}$ & $125^{\circ}$ & $105^{\circ}$ \\
\hline $\boldsymbol{R}_{\mathrm{L}}(-)$ & $0.38 \sim 11$ & $3.6 \sim 12$ & $0.023 \sim 0.078$ \\
\hline $\boldsymbol{G} \boldsymbol{a}_{\mathrm{L}}(-)$ & $(1.5 \sim 260) \times 10^{6}$ & $(460 \sim 3700) \times 10^{6}$ & $(0.02 \sim 0.16) \times 10^{6}$ \\
\hline $\boldsymbol{C}_{\mathrm{L}}(-)$ & $4.0 \sim 120$ & $50 \sim 200$ & $48 \sim 190$ \\
\hline $\boldsymbol{W e}_{\mathrm{L}}(-)$ & $(0.37 \sim 51) \times 10^{-6}$ & $(1.5 \sim 8.1) \times 10^{-6}$ & $(1.3 \sim 7.3) \times 10^{-6}$ \\
\hline $\boldsymbol{F r}_{\mathrm{G}}(-)$ & 0 & \multicolumn{2}{|c|}{$2.4 \sim 9.8$} \\
\hline $\boldsymbol{F r}_{\mathrm{L}}(-)$ & $(1.7 \sim 230) \times 10^{-8}$ & \multicolumn{3}{|c|}{$(1.4 \sim 7.7) \times 10^{-8}$} \\
\hline
\end{tabular}

Note $\boldsymbol{D}_{\mathrm{P}}$ : diameter of packed particle, $\boldsymbol{V}_{\mathrm{G}} \boldsymbol{V}_{\mathrm{L}}, \boldsymbol{V}_{\mathrm{S}}$ : superficial velocity based on empty column for gas, liquid, and solid, respectively, $\theta$ :contact angle, $\mu_{\mathrm{L}}$ : viscosity coefficient of liquid, $\rho_{\mathrm{L}}$ : liquid density, $\sigma_{\mathrm{L}}$ : surface tension, $\boldsymbol{R e}_{\mathrm{L}}=\boldsymbol{V}_{\mathrm{L}} \cdot \boldsymbol{D}_{\mathrm{p}} \cdot \rho_{\mathrm{L}} / \mu_{\mathrm{L}}, \boldsymbol{G} \boldsymbol{a}_{\mathrm{L}}=\boldsymbol{g} \cdot \boldsymbol{D}_{\mathrm{p}}{ }^{3} \cdot \rho_{\mathrm{L}}{ }^{2} / \mu_{\mathrm{L}}{ }^{2}, \boldsymbol{C p}_{\mathrm{L}}=$ $\rho_{\mathrm{L}} \cdot \boldsymbol{g} \cdot \boldsymbol{D}_{\mathrm{p}}{ }^{2} / \sigma_{\mathrm{L}}, \boldsymbol{W} \boldsymbol{e}_{\mathrm{L}}=\rho_{\mathrm{L}} \cdot \boldsymbol{V}_{\mathrm{L}}{ }^{2} \cdot \boldsymbol{D}_{\mathrm{p}} / \sigma_{\mathrm{L}}, \boldsymbol{F} \boldsymbol{r}_{\mathrm{L}}=\boldsymbol{V}_{\mathrm{L}}{ }^{2} /\left(\boldsymbol{g} \cdot \boldsymbol{D}_{\mathrm{p}}\right)$

numbers for the present experiments and BF on the basis of the operation results ${ }^{13)}$ in Japan.

Although many dimensionless numbers for a cold model are desired to agree with the corresponding ones for BF, respectively, it is very difficult to make the requirements satisfy simultaneously. Therefore, we concentrate on Froude number for liquid $\mathrm{Fr}_{\mathrm{L}}$ and varied it over a wide range including $\mathrm{BF}$ condition, because liquid hold-ups greatly depend on $\mathrm{Fr}_{\mathrm{L}} \cdot{ }^{14)}$

\section{Results and Discussion}

\subsection{Influence of Initially Soaked and Unsoaked Beds on Hold-ups under Bad Wettability $\left(\theta \fallingdotseq 70^{\circ}\right)$}

Figures 5, 6, 7, 8 and 9 represent the influence of initially soaked and unsoaked beds on hold-ups for particle diameters $\left(D_{\mathrm{p}}\right)$ of $5.4,8.1,10,19$ and $30 \mathrm{~mm}$, respectively. Under bad particle/liquid wettability condition $\left(\theta \fallingdotseq 70^{\circ}\right), \mathrm{H}_{\mathrm{t}}$ $(\bigcirc)$ and $H_{S}(\triangle)$ for smaller balls in initially unsoaked bed are remarkably smaller than those $(\mathbf{O}, \mathbf{\Delta})$ in initially soaked bed. ${ }^{7,10)}$ The differences between respective hold-ups for initially unsoaked and soaked beds decrease as the ball size increases, and $H_{t}(O)$ and $H_{S}(\triangle)$ for initially unsoaked bed are about $80-90 \%$ as large as those for initially soaked bed when ball size increases over $19 \mathrm{~mm}$. Even if $D_{\mathrm{p}}$ increases up to 40,50 and $60 \mathrm{~mm}$ such as the dripping zone in $\mathrm{BF}, \mathrm{H}_{\mathrm{S}}$ and $\mathrm{H}_{\mathrm{t}}$ for initially unsoaked bed are estimated at about $90 \%$ of those for initially soaked bed by author's equation. ${ }^{15)}$ On the other hand, $\mathrm{H}_{\mathrm{d}}$ in both cases of initially unsoaked ( $\square$ ) and soaked beds ( $\square$ ) have almost the same values except for $D_{\mathrm{p}}=5.4 \mathrm{~mm}$. In the near future, the significant difference in $\mathrm{H}_{\mathrm{d}}$ for $D_{\mathrm{p}}=5.4 \mathrm{~mm}$ should be investigated.

The main cause for these results is considered to be the channeling flow; the restricted flow paths are formed under initially unsoaked bed, ${ }^{7)}$ because the liquid droplets and/or liquid rivulets are easy to flow through the same path with locally higher void fraction. ${ }^{10)}$ Husslage et al. ${ }^{8)}$ also reported that "Once a liquid path was established through the bed, 


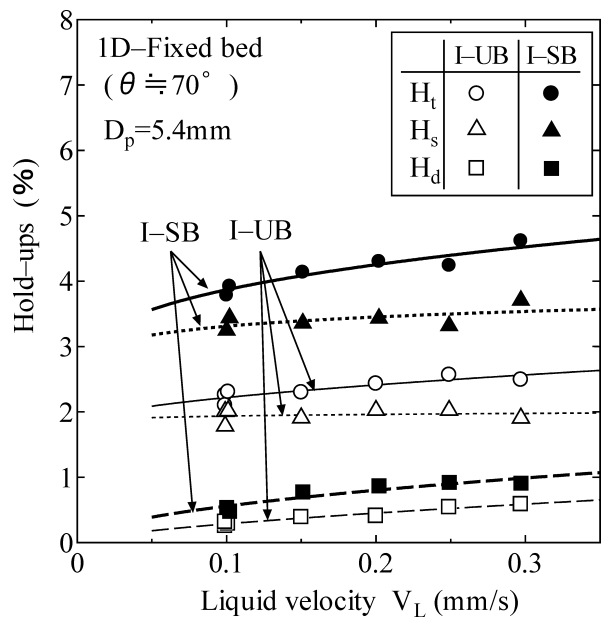

Fig. 5. Influence of initial conditions with unsoaked (I-UB) and soaked beds (I-SB) on hold-ups under bad wettability $\left(D_{\mathrm{p}}=5.4 \mathrm{~mm}\right)$.

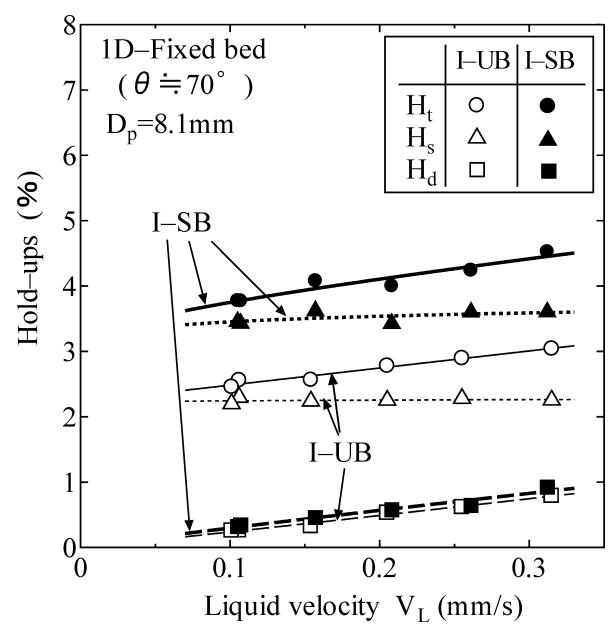

Fig. 6. Influence of initial conditions with unsoaked (I-UB) and soaked beds (I-SB) on hold-ups under bad wettability $\left(D_{\mathrm{p}}=8.1 \mathrm{~mm}\right)$.

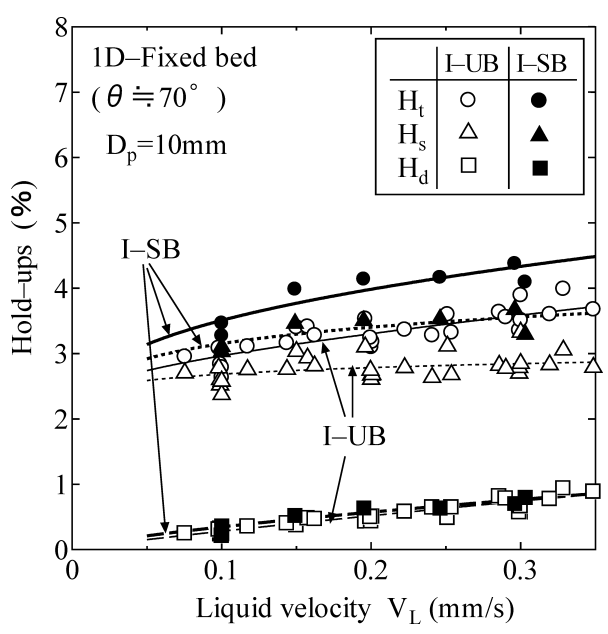

Fig. 7. Influence of initial conditions with unsoaked (I-UB) and soaked beds (I-SB) on hold-ups under bad wettability $\left(D_{\mathrm{p}}=10 \mathrm{~mm}\right)$.

it was also used by the subsequently added fluid; evidently it takes less energy to follow an already wetted path (or rivulet) than to create new interfaces with the particles in

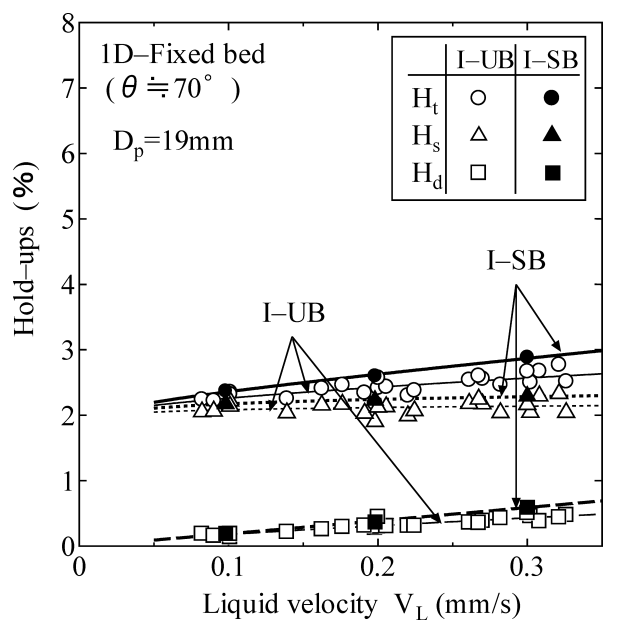

Fig. 8. Influence of initial conditions with unsoaked (I-UB) and soaked beds (I-SB) on hold-ups under bad wettability $\left(D_{\mathrm{p}}=19 \mathrm{~mm}\right)$.

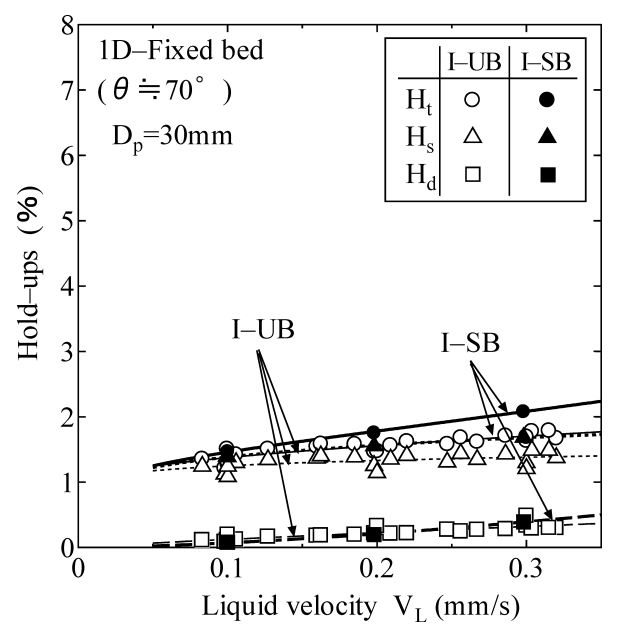

Fig. 9. Influence of initial conditions with unsoaked (I-UB) and soaked beds (I-SB) on hold-ups under bad wettability $\left(D_{\mathrm{p}}=30 \mathrm{~mm}\right)$.

the bed, thus leaving significant volume in the bed unused." Therefore, an effective particle area contacted with liquid droplets and/or liquid rivulets for initially unsoaked bed with smaller ball size is reduced more than that for initially soaked bed.

\subsection{Effect of Contact Angle on Hold-ups in Initially Unsoaked Bed}

Figures 10, 11, 12, 13 and 14 depict the effect of the contact angle $(\theta)$ on liquid hold-ups for $D_{\mathrm{p}}=5.4,8.1,10,19$ and $30 \mathrm{~mm}$ in initially unsoaked fixed bed. The contact angles for fluorine-coated and non-fluorine-coated particles are about $70^{\circ}$ and $10^{\circ}$, respectively. $H_{t}(\bigcirc)$ and $H_{S}(\triangle)$ for bad wettability $\left(\theta \fallingdotseq 70^{\circ}\right)$ are much higher than those $(\mathbf{O}, \boldsymbol{\Delta})$ for good wettability $\left(\theta \fallingdotseq 10^{\circ}\right)$ regardless of particle diameters. On the other hand, in both cases of bad and good wettability $\mathrm{H}_{\mathrm{d}}$ is nearly the same.

Since liquid droplets with good wettability spread out well on the surface of solid, the effective particle area contacted with liquid droplets increases. ${ }^{6}$ Uniformly dispersed liquid on almost all the top surface of the packed bed, however, forms liquid droplets and/or liquid rivulets in some 


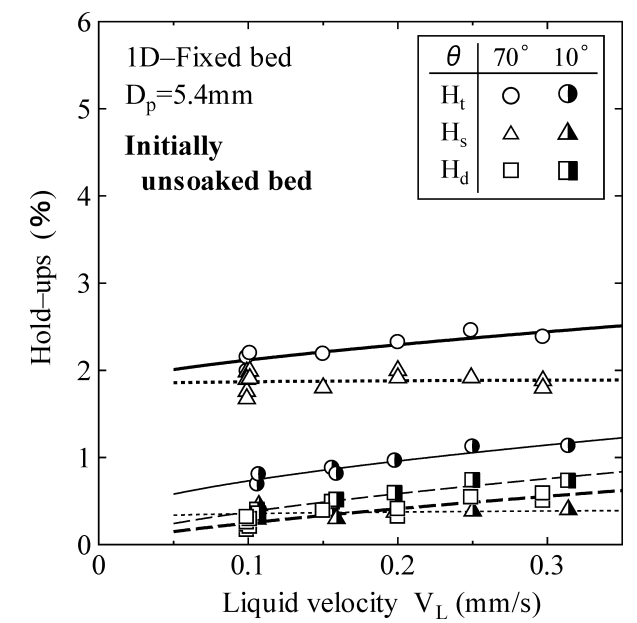

Fig. 10. Effect of contact angle on hold-ups for initially unsoaked bed $\left(D_{\mathrm{p}}=5.4 \mathrm{~mm}\right)$.

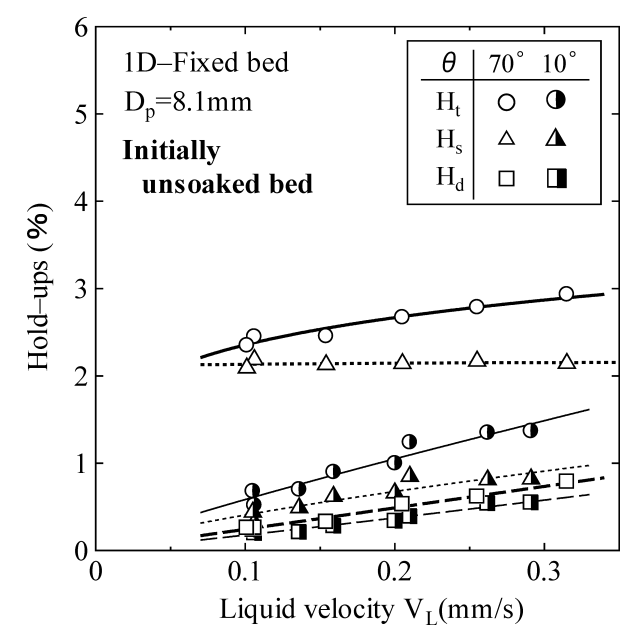

Fig. 11. Effect of contact angle on hold-ups for initially unsoaked bed $\left(D_{\mathrm{p}}=8.1 \mathrm{~mm}\right)$.

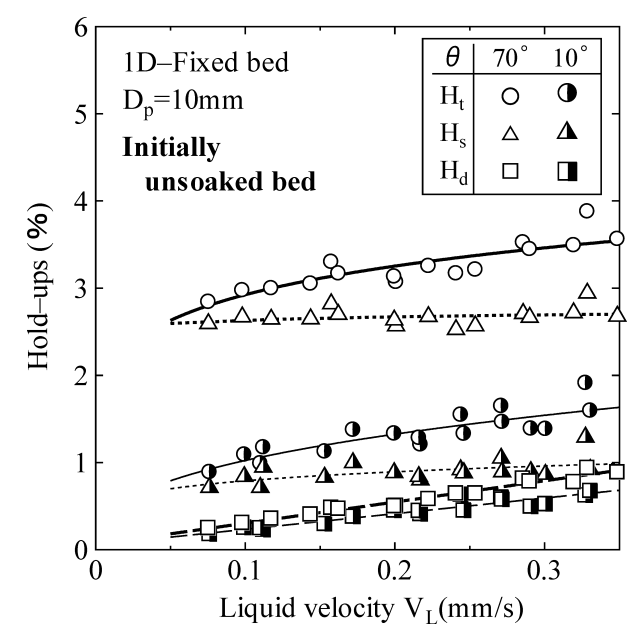

Fig. 12. Effect of contact angle on hold-ups for initially unsoaked bed $\left(D_{\mathrm{p}}=10 \mathrm{~mm}\right)$.

part of the packed bed, from which a few liquid paths branch out. Then liquid droplets and/or liquid rivulets are easy to flow through the same path, pulling each other by their own surface tension. In the case of good wettability, therefore, only a few liquid paths are formed in the initially

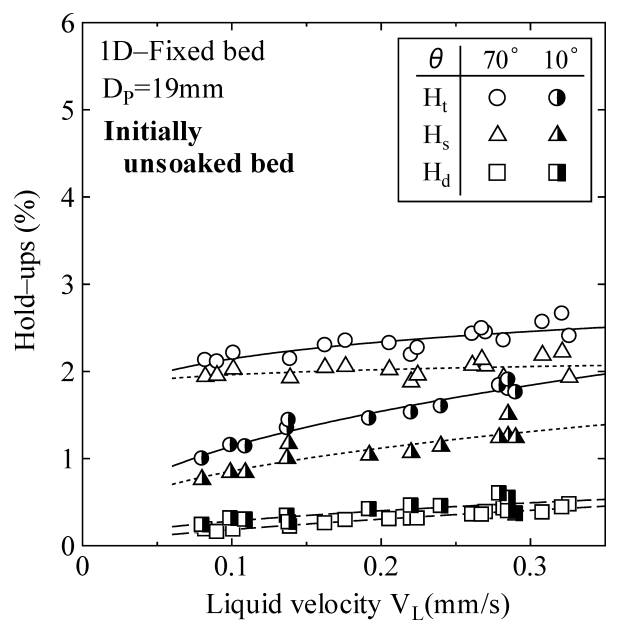

Fig. 13. Effect of contact angle on hold-ups for initially unsoaked bed $\left(D_{\mathrm{p}}=19 \mathrm{~mm}\right)$.

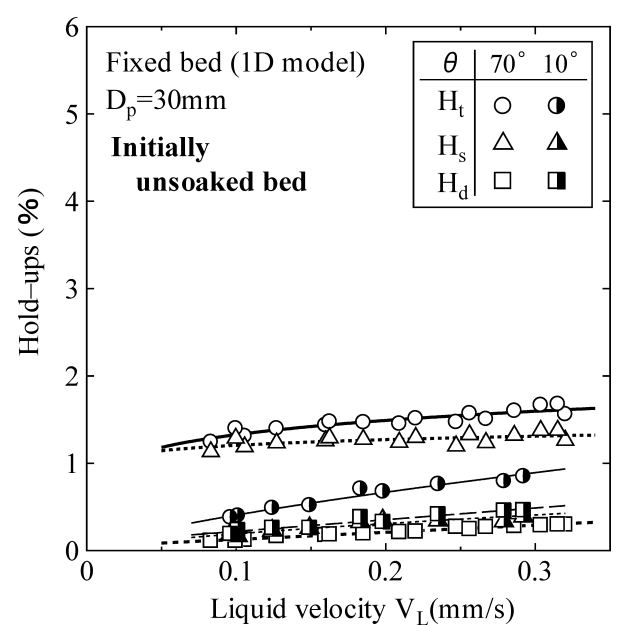

Fig. 14. Effect of contact angle on hold-ups for initially unsoaked bed $\left(D_{\mathrm{p}}=30 \mathrm{~mm}\right)$.

unsoaked packed bed (see visualization experiments later).

Thus, contact angle greatly affects on liquid hold-ups in initially unsoaked bed. The cause is also the channeling flow, in which the liquid droplets and/or liquid rivulets flow easily through the same path in the case of good wettability. ${ }^{10)} \mathrm{Li}$ et al. ${ }^{16)}$ also reported that "In the hydrophilic small particle bed, with increasing attractive capillary force the liquid flows join easily together. As the result, the channeling liquid flows are generated in the small particle side." Therefore, in the case of good wettability the effective particle area contacted with liquid droplets and/or liquid rivulets is much smaller than that in the case of bad wettability.

\subsection{Visualization of Liquid Flow Behavior}

The visualization method was used in order to investigate the channeling phenomenon or the flow behavior of liquid paths in the packed bed. A packed bed of a visualization model was a rectangular parallelepiped made of transparent acrylic resins. The size of the packed bed was $200 \mathrm{~mm}$ in wide, $50 \mathrm{~mm}$ in depth and $170 \mathrm{~mm}$ in height. A liquid distributor of the visualization model installed above the packed bed was composed of 179 injection needles of $0.5 \mathrm{~mm}$ I.D. and $30 \mathrm{~mm}$ in length to disperse the liquid uni- 

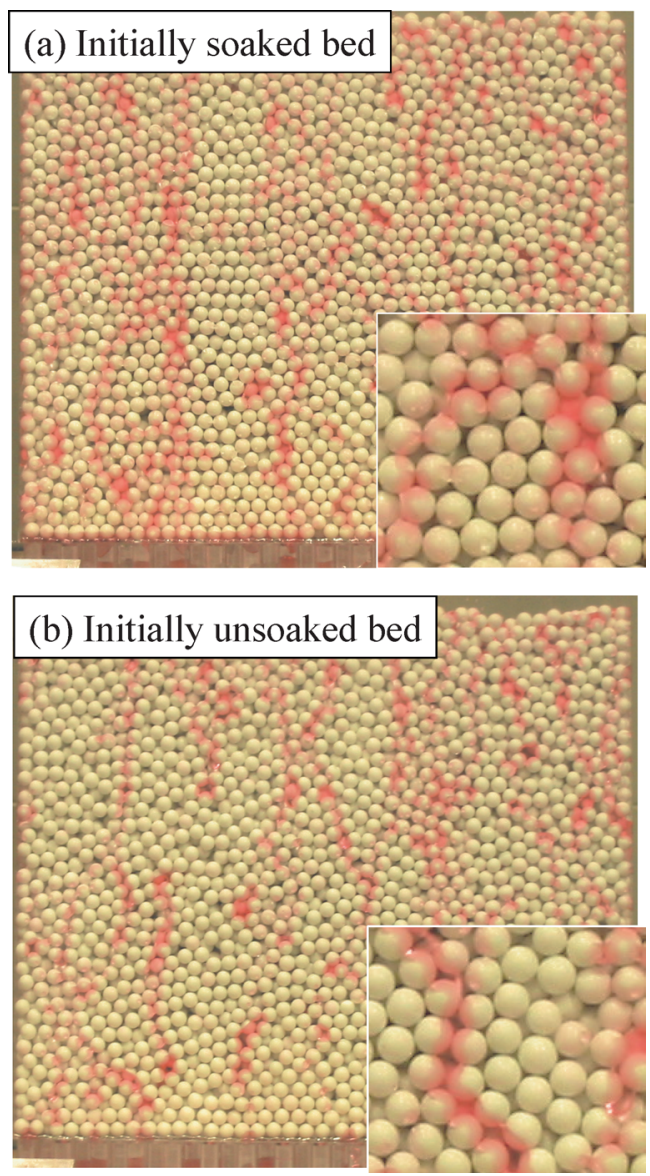

Fig. 15. Visualization of liquid paths in packed bed with bad wettability $\left(\theta \fallingdotseq 65^{\circ}, D_{\mathrm{p}}=5 \mathrm{~mm}\right)$.

formly on the top surface of the packed bed. The filtered tap water was dyed with red ink for easy visualization of liquid paths. Liquid flow behavior and liquid paths were photographed continuously from the front of the packed bed by using a CCD video camera. A digital camera was also used. Contact angles $\theta$ for fluorine-coated particles and non-coated particles decreased to about $65^{\circ}$ and $5^{\circ}$, respectively, because the water was dyed with red ink, which is a surface-active agent.

Visualization photographs for the packed bed of particle diameter of $5.4 \mathrm{~mm}$ with bad wettability $\left(\theta \fallingdotseq 65^{\circ}\right)$ are shown in Fig. 15 to compare the influence of initially soaked and unsoaked beds on liquid paths under the liquid velocity $\left(V_{\mathrm{L}}\right)$ of $0.1 \mathrm{~mm} / \mathrm{s}$. A photograph of a part of the packed bed with higher magnification is also inserted in the bottom right. It is found that in both cases the restricted liquid droplets and/or liquid rivulets are formed within the packed bed. However, liquid droplets and/or liquid rivulets for initially soaked bed (Fig. 15(a)) are much spread out in the void among the particles and on the particle surface in comparison to those of initially unsoaked bed (Fig. 15(b)). In initially soaked bed, there are small liquid droplets and/or thin liquid films standing on the surface of many particles and in many voids even in the parts without liquid rivulets. They are not easy to find in Fig. 15(a), because they are translucency owing to small liquid droplets and/or thin liquid films. On the other hand, under initially unsoaked bed with smaller particle size, many particles hardly contact with liquid droplets and/or liquid rivulets except the
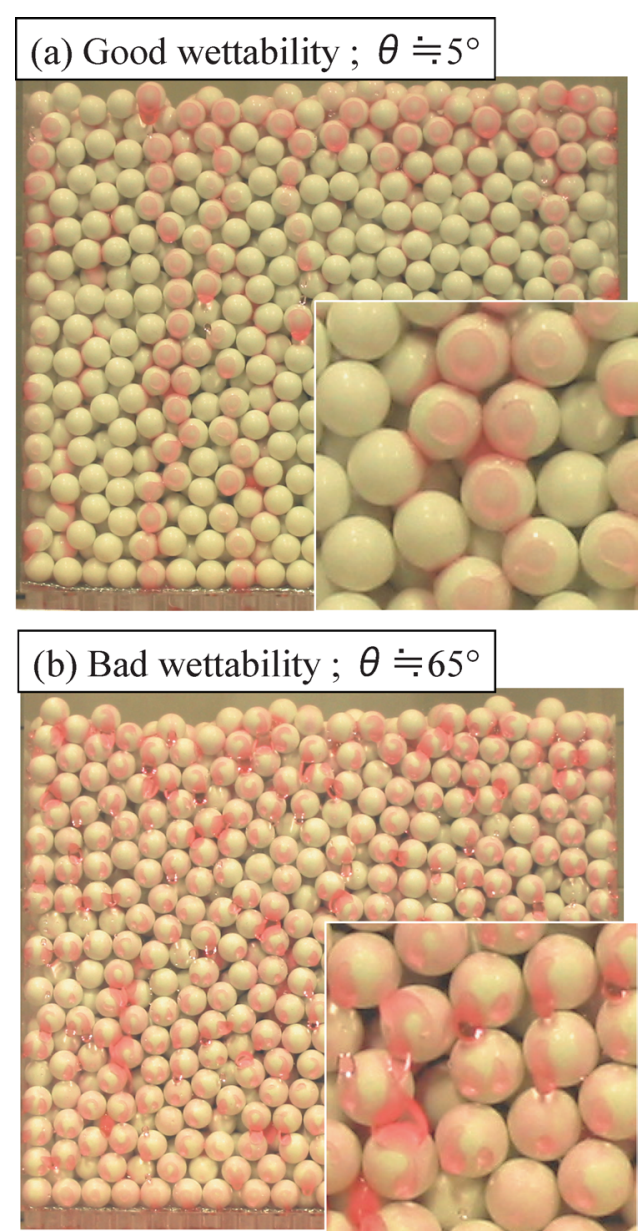

Fig. 16. Visualization of liquid paths for initially unsoaked bed $\left(D_{\mathrm{p}}=10 \mathrm{~mm}\right)$.

parts where the liquid rivulets flow. Consequently, the influence of initially soaked and unsoaked beds on flow behavior is great under the conditions of bad wettability and smaller particle. Furthermore, Husslage ${ }^{17)}$ reported from the laboratory experiments with a stationary packed coke bed (coke sizes of 4 to $10 \mathrm{~mm}$ ) at high temperature $\left(1450-1600^{\circ} \mathrm{C}\right)$ that "The molten slag and the molten iron flow in rivulets, which are not evenly distributed through the bed but tend to follow distinct, narrow paths." Therefore, it is considered that the restricted flow paths, namely channeling flows are formed even in the case with higher contact angles of 105 and $125^{\circ}$ such as the dripping zone in BF.

Figure 16 represents the influence of particle/liquid wettability on the moving behavior of liquid droplets and/or liquid rivulets under initially unsoaked bed packed with $10 \mathrm{~mm}$ particle. Figure 16(a) shows liquid paths in the case of good wettability $\left(\theta \fallingdotseq 5^{\circ}\right)$, and Fig. 16(b) those in the case of bad wettability $\left(\theta \fallingdotseq 65^{\circ}\right)$ under $V_{\mathrm{L}} \fallingdotseq 0.1 \mathrm{~mm} / \mathrm{s}$. It can be seen from Fig. 16(a) that liquid flow develops in packed bed through three or four particle layers from the top surface, and only restricted liquid droplets and/or liquid rivulets are formed under good wettability condition. On the other hand, many liquid droplets are found in bad wettability (Fig. 16(b)), and almost all particles contact with liquid droplets. Thus, it is obvious that the effective area of the particles contacted with liquid droplets and/or liquid rivulets under the condition of bad wettability is much larg- 
er than that in the condition of good wettability through initially unsoaked bed. Generally, total and static hold-ups increase with decreasing contact angle, ${ }^{6}$ because liquid is easy to spread out on the solid surface in the case of good wettability. Under initially unsoaked bed, however, it can be recognized from the above-mentioned liquid flow behavior that total and static hold-ups decrease with decreasing contact angle, because the liquid dispersed uniformly on the top surface of the packed bed is difficult to spread out within the packed bed and flows down in the restricted liquid paths. $^{16)}$

\subsection{Influence of Particle Diameter on Hold-ups}

Figures 17 and 18 represent the variation of hold-ups with particle diameter for initially soaked and unsoaked beds under bad wettability $\left(\theta \fallingdotseq 70^{\circ}\right)$, respectively. Under initially soaked bed (Fig. 17), $\mathrm{H}_{\mathrm{t}}, \mathrm{H}_{\mathrm{S}}$ and $\mathrm{H}_{\mathrm{d}}$ increase monotonically for every liquid velocity $\left(V_{\mathrm{L}}\right)$ as particle size decreases, i.e., as the specific surface area increases. On the other hand, it shows an anomalous phenomenon in the case of initially unsoaked bed (Fig. 18) that $\mathrm{H}_{\mathrm{t}}$ and $\mathrm{H}_{\mathrm{S}}$ have maximum values at about $D_{\mathrm{p}}=10 \mathrm{~mm}$ and decrease abruptly in proportion to decrease in the particle size, despite an increase in the specific surface area. Restricted liquid droplets and/or liquid rivulets are formed in the packed bed with smaller particle size ${ }^{16)}$ as seen from the comparison between Fig. 15(b) and Fig. 16(b), because liquid droplets and/or liquid rivulets are easy to flow through the same path in the case of initially unsoaked bed. ${ }^{8,10)}$ Therefore, the effective area of particles contacted with liquid droplets and/or liquid rivulets decreases for smaller particle size under initially unsoaked bed, and $\mathrm{H}_{\mathrm{t}}$ and $\mathrm{H}_{\mathrm{S}}$ decrease with decreasing particle size. However, above $D_{\mathrm{p}}=10 \mathrm{~mm}, \mathrm{H}_{\mathrm{t}}$, $\mathrm{H}_{\mathrm{S}}$ and $\mathrm{H}_{\mathrm{d}}$ decrease as particle size increases, i.e., as the specific surface area decreases. Thus, the influence of initially soaked and unsoaked beds on liquid hold-ups is very large under bad wettability condition.

As mentioned above, flow distribution is remarkably affected by the initial conditions of the packed particles to be soaked or not. It is very important to investigate what factors, such as liquid density, contact angle, void fraction and particle diameter affect the channeling phenomenon, namely liquid flow behavior. Furthermore, correlation equations for liquid hold-ups in initially unsoaked bed should be derived.

\section{Conclusions}

The characteristics of liquid hold-ups and liquid flow through initially soaked and unsoaked beds were investigated by using a fixed bed of a packed column of 1D model with a relatively large inside diameter of $200 \mathrm{~mm}$. The effect of particle/liquid wettability was examined by changing contact angle $\theta$ as $70^{\circ}$ and $10^{\circ}$. Balls of five kinds of diameters from 5.4 to $30 \mathrm{~mm}$ were used as packing particles. The present investigation leads to the following conclusions:

(1) Total and static hold-ups for initially unsoaked bed under bad wettability $\left(\theta \fallingdotseq 70^{\circ}\right)$ indicate maximum values at about $D_{\mathrm{p}}=10 \mathrm{~mm}$ and decrease abruptly in proportion to decrease in the particle size in spite of an increase in the

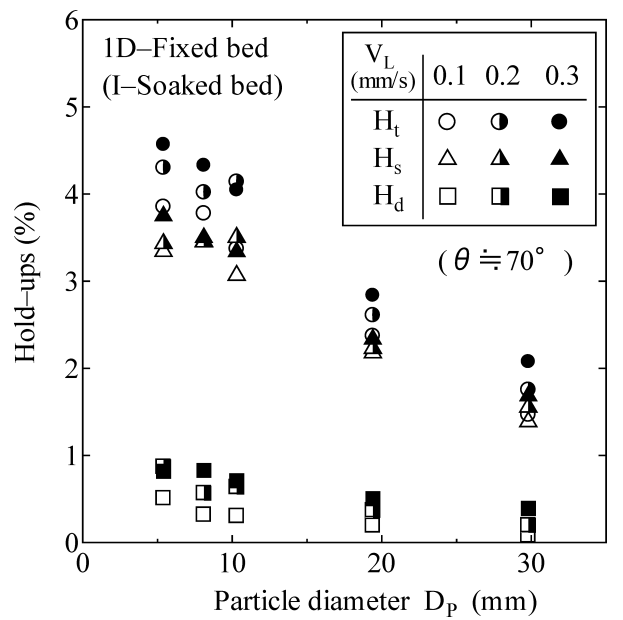

Fig. 17. Relation between hold-ups and particle diameter in initially soaked bed with bad wettability.

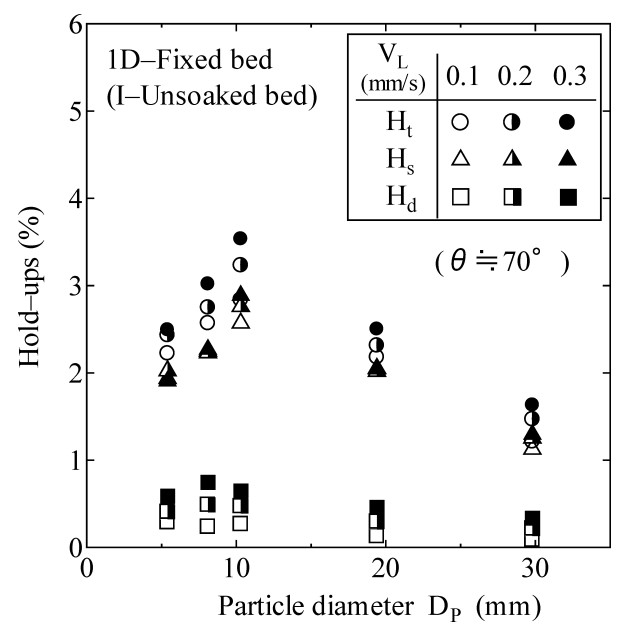

Fig. 18. Relation between hold-ups and particle diameter in initially unsoaked bed with bad wettability.

specific surface area.

(2) Total and static hold-ups for initially unsoaked bed packed with smaller particles below $10 \mathrm{~mm}$ under bad wettability are remarkably smaller than those for initially soaked bed.

(3) Total and static hold-ups for initially unsoaked bed in the case of bad wettability $\left(\theta \fallingdotseq 70^{\circ}\right)$ are much higher than those of good wettability $\left(\theta \fallingdotseq 10^{\circ}\right)$ regardless of particle diameters.

(4) For smaller particle size, visualization experiments of liquid flow behavior reveal under bad wettability condition that the effective area of the particles contacted with liquid droplets and/or liquid rivulets in initially unsoaked bed is much smaller than that in initially soaked bed.

(5) Only restricted liquid droplets and/or liquid rivulets are formed within the packed bed with good wettability condition under initially unsoaked bed, nevertheless liquid is easy to spread out on the solid surface.

\section{REFERENCES}

1) J. Yagi: ISIJ Int., 33 (1993), 619.

2) T. K. Sherwood, G. H. Shipley and F. A. L. Holloway: Ind. Eng. Chem., 30 (1938), 765.

3) A. Mersmann: Chem. Inf.-Techn., 37 (1965), 218.

4) M. Herskowitz and J. M. Smith: AIChE J., 24 (1978), 439.

5) S. P. Zimmerman and K. M. Ng: Chem. Eng. Sci., 41 (1986), 861. 
6) T. Fukutake and V. Rajakumar: Tetsu-to-Hagané, 66 (1980), 1937.

7) G. S. Gupta and S. Bhattacharyya: ISIJ Int., 43 (2003), 1927.

8) W. M. Husslage, T. Bakker, A. G. S. Steeghs, R. H. Heerema and M. A. Reuter: 6th World Cong. of Chem. Eng. 2001, AIChE, New York, (2001), 1643 (CD-ROM).

9) T. Usui, K. Masamori, H. Kawabata and Z. Morita: ISIJ Int., 33 (1993), 687.

10) T. Usui, H. Kawabata and F. Fujita: CAMP-ISIJ, 16 (2003), 792.

11) T. Usui, H. Kawabata, T. Sogo, S. Morii, M. Ichida and Z. Morita: Tetsu-to-Hagané, 82 (1996), 899.
12) H. L. Shulman, C. F. Ullrich and N. Walls: AIChE J., 1 (1955), 247.

13) M. Naito: Private communication, (2003).

14) A. Alidilar, A. Bicer and A. Murathan: Chem. Eng. Commum., 128 (1994), 95.

15) H. Kawabata, K. Shinmyou, T. Harada and T. Usui: ISIJ Int., 45 (2005), 1474.

16) M. Li, Y.Bando, T. Tsuge, K. Yasuda and M. Nakamura: Chem. Eng. Sci., 56 (2001), 5969.

17) W. M. Husslage: Doctoral Thesis, Delft University of Technology, Netherlands, (2004). 